Purdue University

Purdue e-Pubs

CTRC Research Publications

Cooling Technologies Research Center

2012

\title{
A Study of Critical Heat Flux during Flow Boiling in Microchannel Heat Sinks
}

T. Chen

S V. Garimella

Purdue University, sureshg@purdue.edu

Follow this and additional works at: http://docs.lib.purdue.edu/coolingpubs

Chen, T. and Garimella, S V., "A Study of Critical Heat Flux during Flow Boiling in Microchannel Heat Sinks" (2012). CTRC Research Publications. Paper 215.

http://dx.doi.org/DOI: 10.1115/1.4004715

This document has been made available through Purdue e-Pubs, a service of the Purdue University Libraries. Please contact epubs@purdue.edu for additional information. 


\section{A Study of Critical Heat Flux During Flow Boiling in Microchannel Heat Sinks}

\section{Tailian Chen}

Department of Mechanical Engineering, Gonzaga University, Spokane, WA 99258-0026 e-mail: chent@gonzaga.edu

\section{Suresh V. Garimella \\ Cooling Technologies Research Center, an NSF IUCRC, \\ School of Mechanical Engineering and Birck Nanotechnology Center, Purdue University, \\ West Lafayette, IN 47907-2088 e-mail: sureshg@purdue.edu}

The cooling capacity of two-phase transport in microchannels is limited by the occurrence of critical heat flux $(\mathrm{CHF})$. Due to the nature of the phenomenon, it is challenging to obtain reliable CHF data without causing damage to the device under test. In this work, the critical heat fluxes for flow boiling of FC-77 in a silicon thermal test die containing 60 parallel microchannels were measured at five total flow rates through the microchannels in the range of 20-80 $\mathrm{ml} / \mathrm{min}$. CHF is caused by dryout at the wall near the exit of the microchannels, which in turn is attributed to the flow reversal upstream of the microchannels. The bubbles pushed back into the inlet plenum agglomerate; the resulting flow blockage is a likely cause for the occurrence of CHF which is marked by an abrupt increase in wall temperature near the exit and an abrupt decrease in pressure drop across the microchannels. A database of 49 data points obtained from five experiments in four independent studies with water, R-113, and FC-77 as coolants was compiled and analyzed. It is found that the CHF has a strong dependence on the coolant, the flow rate, and the area upon which the heat flux definition is based. However, at a given flow rate, the critical heat input (total heat transfer rate to the coolant when CHF occurs) depends only on the coolant and has minimal dependence on the details of the microchannel heat sink (channel size, number of channels, substrate material, and base area). The critical heat input for flow boiling in multiple parallel microchannels follows a well-defined trend with the product of mass flow rate and latent heat of vaporization. A power-law correlation is proposed which offers a simple, yet accurate method for predicting the CHF. The thermodynamic exit quality at CHF is also analyzed and discussed to provide insights into the CHF phenomenon in a heat sink containing multiple parallel microchannels. [DOI: 10.1115/1.4004715]

Keywords: critical heat flux, CHF, maximum cooling capacity, flow boiling, microchannel heat sinks, electronics cooling

\section{Background}

As electronic devices have advanced toward higher-performance operation, the concurrent reduction in size and weight of the devices have intensified the thermal management challenge. As recently outlined by Garimella et al. [1], one of the major challenges in thermal management of electronics is the dissipation of high heat fluxes. Two-phase microchannel cooling has been identified as a promising alternative due to its high performance, compactness, and compatibility with device manufacturing processes. The critical heat flux (CHF) represents the upper limit to the cooling capacity of two-phase technologies and is an important consideration in the system design. Although CHF for conventional flow boiling has been extensively studied [2], CHF data for boiling heat transfer in microchannels are still scarce, especially for boiling in heat sinks with multiple parallel microchannels.

Early studies of CHF for conventional flow boiling [3-5], followed by those of Katto [6-9] established the basis for our present understanding of the CHF phenomenon and led to well-known correlations that incorporated several nondimensional parameter groups: Weber number, $\mathrm{We}=\mathrm{G}^{2} \mathrm{~L} /\left(\sigma \rho_{1}\right)$, density ratio, $\rho_{\mathrm{v}} / \rho_{1}$, length-diameter ratio, $\mathrm{L} / \mathrm{D}_{\mathrm{e}}$, and inlet subcooling, $\Delta \mathrm{h}_{\mathrm{i}} / \mathrm{h}_{\mathrm{fg}}$. In general, the CHF increases with increasing mass flux and inlet subcooling.

For flow boiling in small channels, Lazarek and Black [10] measured $\mathrm{CHF}$ and critical quality (vapor quality in the tube

Contributed by the Heat Transfer Division of ASME for publication in the JouRnaL of Heat Transfer. Manuscript received December 3, 2010; final manuscript received July 18, 2011; published online November 18, 2011. Assoc. Editor: W. Q. Tao. cross-section where CHF occurs) with refrigerant $\mathrm{R}-113$ in a vertical tube of diameter $3.1 \mathrm{~mm}$ and found that CHF increased with mass flux. The following correlation for critical quality accounting for inlet subcooling was proposed:

$$
\mathrm{x}_{\mathrm{e}, \mathrm{c}}=1-6.075 \times 10^{-3} \mathrm{GD}_{\mathrm{h}}^{0.25}\left(\frac{\mathrm{D}_{\mathrm{e}}}{\mathrm{L}_{\mathrm{h}}}\right)^{0.59}\left[1+3.11\left(\frac{\Delta \mathrm{h}_{\mathrm{in}}}{\mathrm{h}_{\mathrm{fg}}}\right)\right]
$$

A study of CHF for water flowing in tubes of diameter from 0.3 to $2.7 \mathrm{~mm}$ was conducted by Vandervort et al. [11] under the following conditions: mass fluxes of $5000-40,000 \mathrm{~kg} / \mathrm{s}-\mathrm{m}^{2}$, exit subcooling of 40 to $135 \mathrm{~K}$, length-to-diameter ratios of 2-50, and exit pressure of $0.2-2.2 \mathrm{MPa}$. The values for $\mathrm{CHF}$ were measured to be in the range of $20-80 \mathrm{MW} / \mathrm{m}^{2}$ and increased with an increase in mass flux and subcooling, but decreased with increasing channel diameter. CHF was also found to be weakly dependent on exit pressure and tube length-to-diameter ratio. In a study of flow boiling of water in a $2.98 \mathrm{~mm}$ diameter horizontal tube of length 0.91 $\mathrm{m}$, Yu et al. [12] found that the CHF occurred at an exit quality in the range from 0.5 to 1.0 , and that the exit quality decreased with decreasing mass flux, in contrast to results found in larger tubes [13].

CHF data for flow boiling in multiple parallel minichannels and microchannels are scarce. Bowers and Mudawar [14] studied the effects of inlet subcooling (from 10 to $30 \mathrm{~K}$ ) and flow rate (from 19 to $95 \mathrm{ml} / \mathrm{min}$ ) on CHF for flow boiling of R-113 in a minichannel heat sink (three channels, each of diameter $2.54 \mathrm{~mm}$ ) and a microchannel heat sink (17 channels, each of diameter $0.51 \mathrm{~mm}$ ). They found CHF to be independent of inlet subcooling and it 
increased with increasing flow rate. The following correlation was found to provide a good prediction based on their twelve CHF data points including five for the $2.54 \mathrm{~mm}$ channels and seven for the $0.510 \mathrm{~mm}$ channels

$$
\frac{\mathrm{q}_{\mathrm{c}, \mathrm{p}}^{/ /}}{\mathrm{Gh}_{\mathrm{fg}}}=0.16 \mathrm{We}^{-0.19}\left(\frac{\mathrm{L}_{\mathrm{h}}}{\mathrm{D}}\right)^{-0.54} .
$$

By using a heat sink containing 21 microchannels, each $0.215 \mathrm{~mm}$ wide and $0.821 \mathrm{~mm}$ deep, Qu and Mudawar [15] generated two sets of CHF data points for water at two subcooling levels; each set included nine $\mathrm{CHF}$ data points for nine flow rates in the range of $86-68 \mathrm{~kg} / \mathrm{s}-\mathrm{m}^{2}$. They also examined several CHF correlations available in the literature developed for conventional flow boiling for their applicability to flow boiling in single minichannels and microchannels. Although the correlation of Katto and Ohno [16] gave a reasonable prediction (within $\pm 50 \%$ ) of CHF for boiling in single circular tubes based on data from Refs. [3-5,10,17,18] for water and R-113, it was found inappropriate for prediction of CHF for boiling in mini/micro heat sinks of multiple parallel channels. The following correlation was proposed based on a total of $21 \mathrm{CHF}$ data points including those from Ref. [14]

$$
\frac{\mathrm{q}_{\mathrm{c}, \mathrm{p}}^{/ /}}{\mathrm{Gh}_{\mathrm{fg}}}=33.43\left(\frac{\rho_{\mathrm{v}}}{\rho_{1}}\right)^{1.11} \mathrm{We}^{-0.21}\left(\frac{\mathrm{L}_{\mathrm{h}}}{\mathrm{D}_{\mathrm{e}}}\right)^{-0.36} .
$$

Simultaneous measurements and high-speed visualizations were performed with the dielectric liquid FC-77 in Refs. [19,20] to study effects of heat flux, mass flux, channel size, and instabilities on the flow pattern development during flow boiling in multiple microchannels. As instabilities occurred, the flow patterns changed dramatically due to the flow reversal upstream of the microchannels. CHF for FC-77 was also measured by Chen and Garimella [21] corresponding to three flow rates in the range of $30-50 \mathrm{ml} / \mathrm{min}$.

As discussed in a recent review by Roday and Jensen [22], compared with flow boiling in a single tube, CHF for flow boiling in multiple parallel microchannels is more complicated. Bergles and Kandlikar [23] noted that CHF in parallel microchannels seems to be a result of instability rather than liquid dryout which is considered the reason for CHF in boiling in single channels. They further suggested that throttling flow at the entrance of each channel could suppress instabilities and thus increase the CHF. However, CHF values measured by Kuo and Peles [24] during flow boiling of water in a silicon-based microchannel heat sink under various flow conditions indicated that $\mathrm{CHF}$ was caused by dryout of the channel wall.

In the present work, a silicon thermal test chip $(12.7 \mathrm{~mm}$ by $12.7 \mathrm{~mm}$ ) containing 60 multiple parallel microchannels was used to investigate flow boiling phenomena and the maximum cooling capacity over a range of conditions. The perfluorinated dielectric coolant FC-77 is the coolant selected. The results from the present study are combined with those from the literature into a database of CHF data that are analyzed to shed light on the CHF phenomenon in flow boiling in multiple parallel microchannels.

\section{Experiments}

2.1 Test Loop. A schematic diagram of the test loop is shown in Fig. 1. A magnetically coupled gear pump drives the coolant through the closed loop and a precision flow meter (McMillan Company, model S-114) monitors the flow rate. A preheater before the test section controls the degree of coolant inlet subcooling and a heat exchanger installed after the test section rejects the heat added in the test section to air through a fancooled heat sink. The two degassing ports shown in Fig. 1 are used to degas the liquid in the reservoir and evacuate air from the test loop. After the coolant is fully degassed, it is charged into the

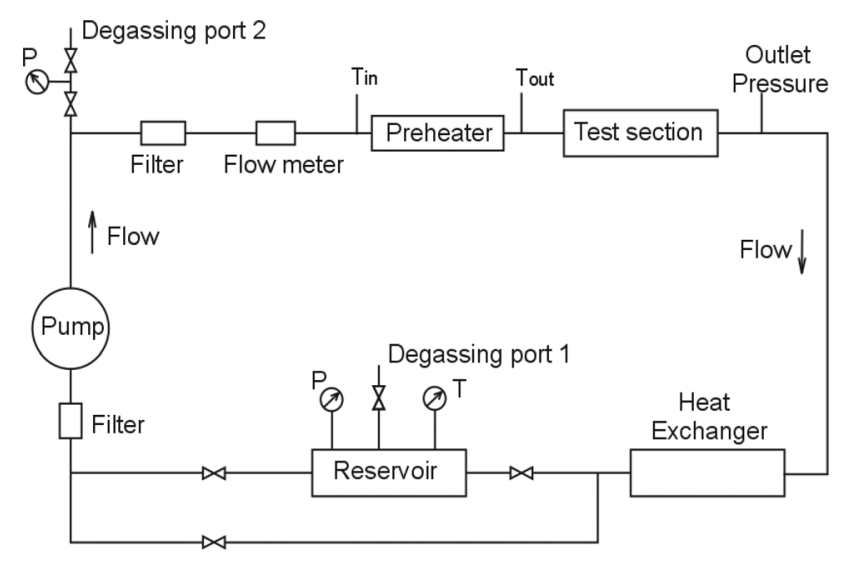

Fig. 1 Experimental test loop

evacuated test loop. The pressure in the outlet manifold of the test section is maintained at atmospheric pressure by the bellows-like reservoir. Details of the degassing scheme and the test procedures are available in Ref. [25]. The boiling point of the fully degassed perfluorinated dielectric liquid, $\mathrm{FC}-77$, is $97^{\circ} \mathrm{C}$ at one atmosphere pressure.

The experiments were performed at five flow rates in the range of $20-80 \mathrm{ml} / \mathrm{min}$ (at room temperature), corresponding to a mass flux range of $253.7-1015.0 \mathrm{~kg} / \mathrm{s}-\mathrm{m}^{2}$ and a Reynolds number range of 31 to 124 for single-phase flow in the microchannels. The coolant temperature at the inlet was maintained at $71 \pm 1.0^{\circ} \mathrm{C}$ for all flow rates. For each flow rate, experiments were started with a low heat input at which single-phase flow exists in the microchannels. The heat input was then incrementally increased and data were obtained when the flow and temperatures reach a steady state at each heat input. The experiments were terminated for each flow rate when the temperature sensor near the exit detected an abrupt increase in wall temperature, which indicated the occurrence of $\mathrm{CHF}$ in the microchannels.

2.2 Test Section. Figure $2(a)$ is a photograph of the printed circuit board (PCB) with the silicon test die at the center. The mounting details of the silicon die on the PCB are shown in Fig. $2(b)$. The $12.7 \mathrm{~mm} \times 12.7 \mathrm{~mm} \times 0.373 \mathrm{~mm}$ silicon die fabricated by Delphi Electronics and Safety has 25 heating elements (doped silicon wells), each of an approximate size $2.54 \mathrm{~mm}$ by $2.54 \mathrm{~mm}$ and a nominal resistance of $26.4 \Omega$ at room temperature. A diode temperature sensor (consisting of five pn junctions in series) is fabricated at the center of each heating element. A uniform heat input was provided by connecting the 25 heating elements in parallel to a direct current power supply. Figure 3 shows the arrangement of the 25 heating elements (U1-U25) with the flow going from right to left. Sixty parallel microchannels, each 100 $\mu \mathrm{m}$ wide and $389 \mu \mathrm{m}$ deep, were machined by saw-cutting the silicon die on the opposite side of the heating elements and temperature sensors. The width of the fins between the microchannels is $100 \mu \mathrm{m}$. The details of the assembled test section are available in Chen and Garimella [19]. Two thermocouples inserted into the inlet and outlet manifolds measure the local fluid temperatures. A differential pressure transducer is used to measure pressure drop across the microchannels.

The voltage drop across a diode biased at a constant electrical current has a temperature dependence of approximately $-2 \mathrm{mV} /$ ${ }^{\circ} \mathrm{C}$. In this work, the exact voltage-temperature relationship for each temperature sensor (five diodes in series) was calibrated by placing the assembled test section in a controlled, uniform-temperature oven. During the calibration, five thermocouples positioned at five different locations on the assembled test section monitored its temperature. A thermal steady state was considered to 


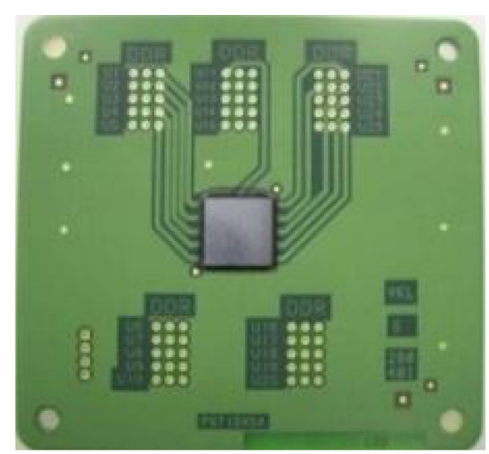

(a)

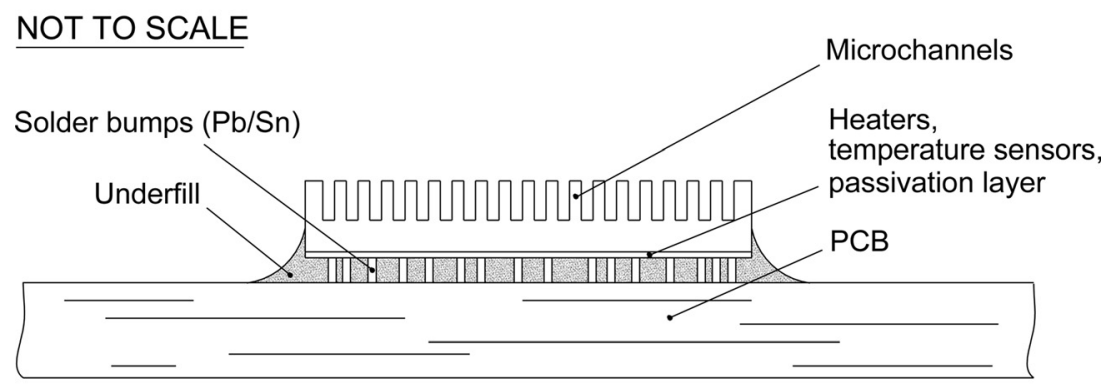

(b)

Fig. 2 (a) Photograph of the printed circuit board (PCB) with the silicon die $(12.7 \mathrm{~mm} \times 12.7 \mathrm{~mm} \times 0.373 \mathrm{~mm})$ at the center and $(b)$ mounting details of the silicon die on the PCB

have been reached when the readings from all five thermocouples were the same and remained unchanged with time. The voltages across the 25 diode temperature sensors and the resistances of the 25 heating elements were recorded at this time. The voltage-temperature relationships for all 25 diode temperature sensors so obtained are represented by $\mathrm{V}=-0.0104 \mathrm{~T}_{\mathrm{b}}\left({ }^{\circ} \mathrm{C}\right)+3.5125$. This relationship was subsequently used in boiling experiments to determine the temperature, $\mathrm{T}_{\mathrm{b}}$, from the measured voltage drop, $\mathrm{V}$, across each temperature sensor. The resistance of each heating element increases almost linearly with temperature, at a rate of approximately $2 \Omega$ for a temperature increase of $100^{\circ} \mathrm{C}$; this resistance variation with temperature was taken into account in calculating the heat generation by the heating elements. After the calibration was completed, the five thermocouples were removed from the test section and were not used during the boiling experiments.

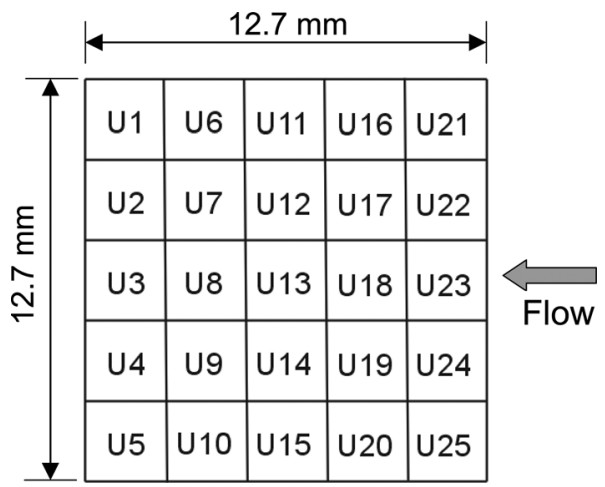

Fig. 3 The arrangement of 25 heating elements U1-U25 (not shown in the figure are 25 diode temperature sensors, each located at the center of each heating element)

\section{Data Reduction and Uncertainty Analysis}

An energy balance can be written for each of the 25 heating elements

$$
\dot{\mathrm{q}}_{\text {total }}=\dot{\mathrm{q}}_{\mathrm{fluid}}+\dot{\mathrm{q}}_{\text {loss }}
$$

in which $\dot{\mathrm{q}}_{\text {total }}$ is the total heat generation calculated directly from the applied voltage, $\mathrm{V}$, and the resistance of the heating element, $\mathrm{R} ; \dot{\mathrm{q}}_{\text {fluid }}$ is the heat transferred to the coolant. $\dot{\mathrm{q}}_{\text {loss }}$ is the heat loss obtained by measuring the heat input to the assembled test section at each temperature before the test loop was charged with coolant; a relationship is thus obtained between the heat loss and the heat sink base temperature, $\mathrm{T}_{\mathrm{b}}$, for each heating element. For instance, the heat loss for the heating element $\mathrm{U} 3$ is represented by $\dot{\mathrm{q}}_{\text {loss }}=0.1229 \mathrm{~T}_{\mathrm{b}}-2.7821$. This heat loss-temperature relationship is used in Eq. (4) to determine the heat transferred to the fluid, $\dot{\mathrm{q}}_{\text {fluid }}$, during the boiling experiments. Local heat transfer coefficients, h, were calculated as

$$
\mathrm{h}=\dot{\mathrm{q}}_{\mathrm{fluid}} /\left[\left(\mathrm{T}_{\mathrm{w}}-\mathrm{T}_{\mathrm{sat}}\right) \mathrm{A}_{\mathrm{b}}\right] .
$$

In Eq. (5), $A_{b}$ is the heating element area, $0.0645 \mathrm{~cm}^{2}$, which is $1 / 25$ th of the total heat sink base area. In this work, the local heat transfer coefficient near the exit of the microchannels is calculated based on $\mathrm{T}_{\text {sat }}$ being equal to the atmospheric pressure, at which the channel exit manifold is maintained. The local wall temperature near the exit, $\mathrm{T}_{\mathrm{w}}$, is obtained by correcting the corresponding local temperature measured at the base of the microchannel substrate $T_{b}$ using

$$
\mathrm{T}_{\mathrm{w}}=\mathrm{T}_{\mathrm{b}}-\left(\dot{\mathrm{q}}_{\text {fluid }} \mathrm{t}_{\mathrm{b}}\right) /\left(\mathrm{kA}_{\mathrm{b}}\right)
$$

in which $t_{b}$ is the distance $(=0.373 \mathrm{~mm})$ from the heat sink base to the bottom of the microchannels and $\mathrm{k}$ is the silicon thermal conductivity. 


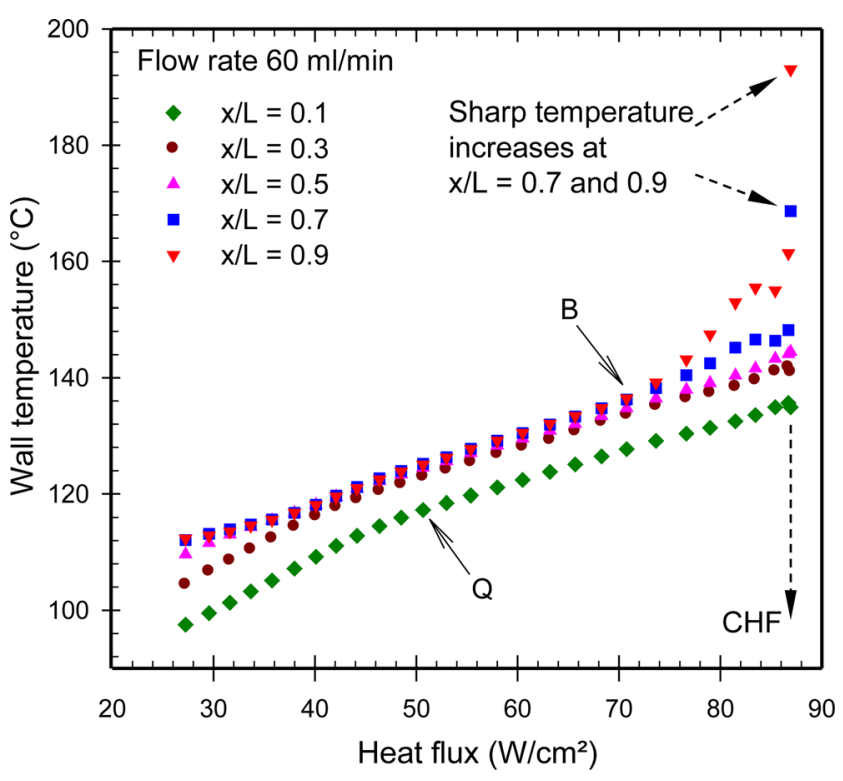

(a)

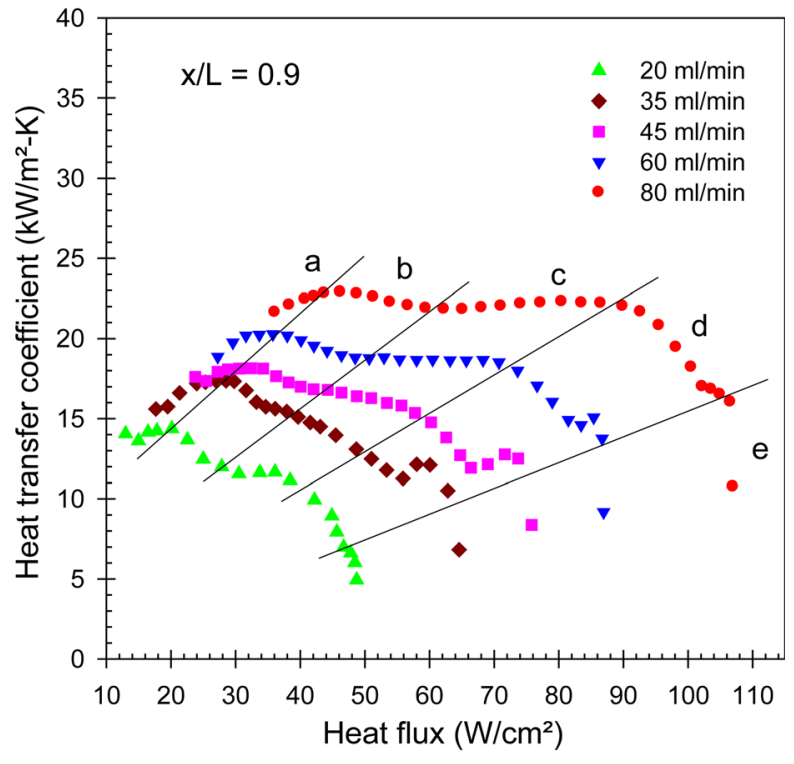

(b)

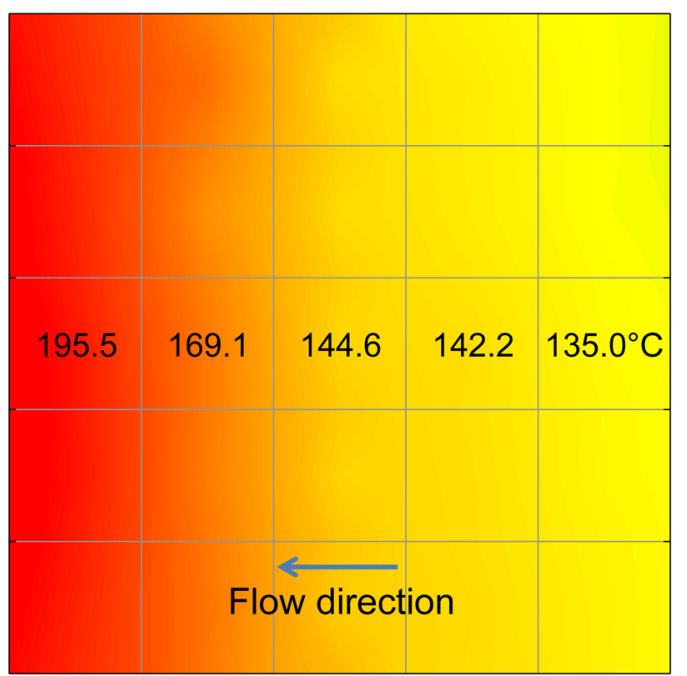

(c)

Fig. 4 (a) Wall temperature measurements along the flow direction at the flow rate of $60 \mathrm{ml} / \mathrm{min}$ (sharp increases are noted as the heat flux is increased from the point marked $B$ ) and (b) heat transfer coefficients, $h$, obtained just prior to the exit of the microchannels for the five flow rates considered in the present study, and (c) wall temperature distribution when the CHF occurs (heat flux of $86.7 \mathrm{~W} / \mathrm{cm}^{2}$ ) at the flow rate of $60 \mathrm{ml} / \mathrm{min}$ (Included in the image are wall temperatures measured from the five diode sensors along the midline); heat flux is based on the substrate base area $A_{b}$ and $h$ is defined in Eq. (5)

Uncertainties in the measured quantities presented in this work are $\pm 2.5-10.0 \%$ in the flow rate over the range considered, and $0.69-8.62 \%$ in the pressure drop measurements for measured values in the range of 2000-25000 Pa; the larger uncertainties occur at the smaller measured values. The wall temperature uncertainty comes from calibration of the temperature sensors and from correction for the temperature drop from the heat sink base as in Eq. (6). The wall temperature uncertainty is estimated to be $\pm 0.2^{\circ} \mathrm{C}$. Uncertainties in the heat transfer coefficient arise from those in the determination of heat transfer rate into the microchannels and the wall temperature measurements. Following the procedure described by Kline and McClintock [26], the uncertainty in heat transfer coefficient is estimated to be in the range of $2-12 \%$, with the larger uncertainties occurring at the lower heat fluxes.

\section{CHF Physical Mechanism}

The heat transfer performance over a broad range of heat fluxes from initiation of boiling to CHF is shown in Fig. 4, in which heat fluxes are based on the heat sink base area, $A_{\mathrm{b}}$. Figure 4(a) shows the measured wall temperatures from the five temperature sensors along the midline of the heat sink at the flow rate of $60 \mathrm{ml} / \mathrm{min}$; $\mathrm{x} / \mathrm{L}=0.1$ is closest to the inlet and $\mathrm{x} / \mathrm{L}=0.9$ is closest to the exit. Figure 4(b) shows the development of boiling regimes with increasing heat flux based on the heat transfer coefficients measured near the exit corresponding to the temperature sensor at $\mathrm{x} / \mathrm{L}=0.9$ at the five flow rates. Different boiling regimes "a" through "e" are marked in the figure. The regimes "a" and "b" correspond to boiling at the lowest heat fluxes for each flow rate, within which the flow pattern in the microchannels develops quickly through bubbly flow, slug flow, elongated slugs, and then annular flow. A detailed discussion by the authors of these boiling regimes and the effect of instabilities is available in Ref. [27]; the discussion here is limited to the boiling regimes "c," "d," and "e" in Fig. $4(b)$ to shed light on the physical mechanisms for the occurrence of CHF in microchannels.

It is seen in Fig. 4(a) that as the heat flux is increased past the point labeled B, significant increases in wall temperature are 


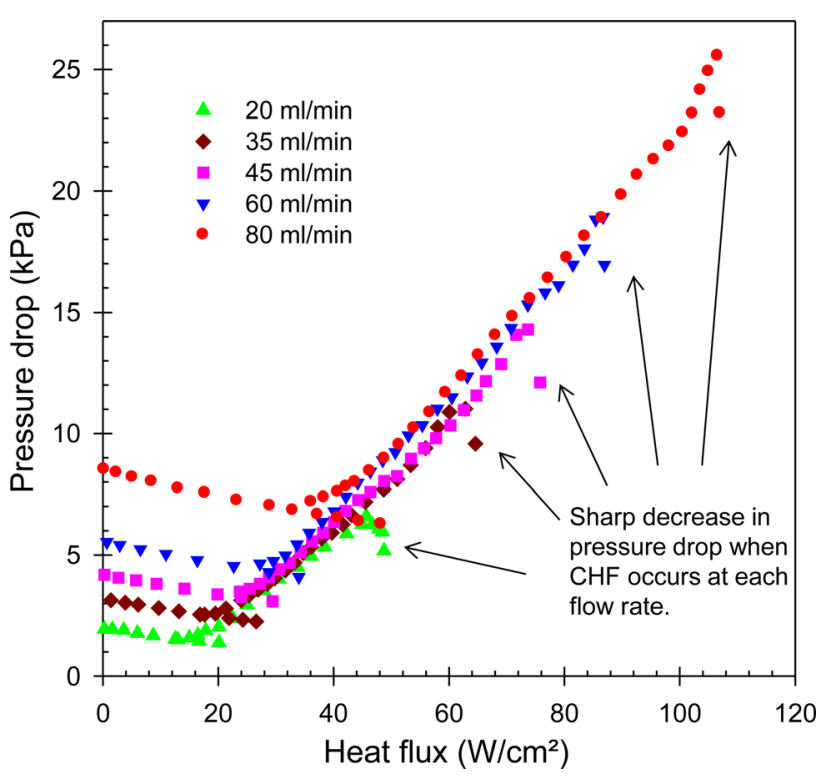

Fig. 5 Pressure drop measurements over the entire heat flux range including both single-phase and two-phase flow at all five flow rates; the heat flux is based on the substrate base area $\mathbf{A}_{b}$

detected at the downstream end $(\mathrm{x} / \mathrm{L}=0.9$ and 0.7$)$; the increase at the exit $(x / L=0.9)$ is significantly larger than that at $x / L=0.7$. As the heat flux is reached (with a small step increase) to $86.7 \mathrm{~W} / \mathrm{cm}^{2}$ at this flow rate $(60 \mathrm{ml} / \mathrm{min})$, an abrupt increase in wall temperatures was recorded. Such an abrupt increase in wall temperature for a small increase in heat flux is indicative of $\mathrm{CHF}$ being reached. The wall temperature distribution across the entire heat sink corresponding to this $\mathrm{CHF}\left(86.7 \mathrm{~W} / \mathrm{cm}^{2}\right)$ is presented in Fig. 4(c) clearly showing that the wall temperatures at the downstream end are significantly higher than those at the upstream end. It is also noted the wall temperatures in the lateral direction (perpendicular to the flow direction) are nearly the same, indicative of a relatively uniform flow distribution among the parallel microchannels. The boiling regime marked "e" in Fig. 4(b) corresponds to values at $\mathrm{CHF}$ for the five flow rates, and show abrupt decreases in heat transfer coefficient. Prior to CHF, when boiling occurs in the regime marked "c", instabilities are initiated due to periodic flow reversal in the upstream region of the microchannels. Such flow reversals were visually observed and documented by the authors in Ref. [19] via high-speed visualization; moreover, the corresponding instabilities were also reflected as sharp increases in the magnitude of fluctuations recorded in the pressure drop across the microchannels. The flow patterns throughout the length of the microchannels are dramatically changed due to this instability. The flow in the upstream region alternates with time between normal and reversed flow, whereas the flow in the downstream region alternates correspondingly between churn and wispy-annular flow. The vapor quality in wispy-annular flow is much higher than that in churn flow due to the disrupted flow downstream at the constant heat input provided to the microchannels. As the heat flux increases, the time interval during which wispy-annular flow is observed increases due to the stronger flow reversal upstream; this results in momentary wall dryout due to a depletion of liquid in the downstream region of the microchannels. The extended period of dryout with increasing heat flux is responsible for the greater increase in wall temperature in Fig. 4(a) and the decrease in heat transfer coefficient in Fig. 4(b) in the boiling regime "d".

The CHF phenomenon in microchannel heat sinks appears, from this work, to be tied closely to the upstream flow patterns. Instabilities result in bubbles being pushed back into the inlet plenum periodically. As the instabilities become stronger with

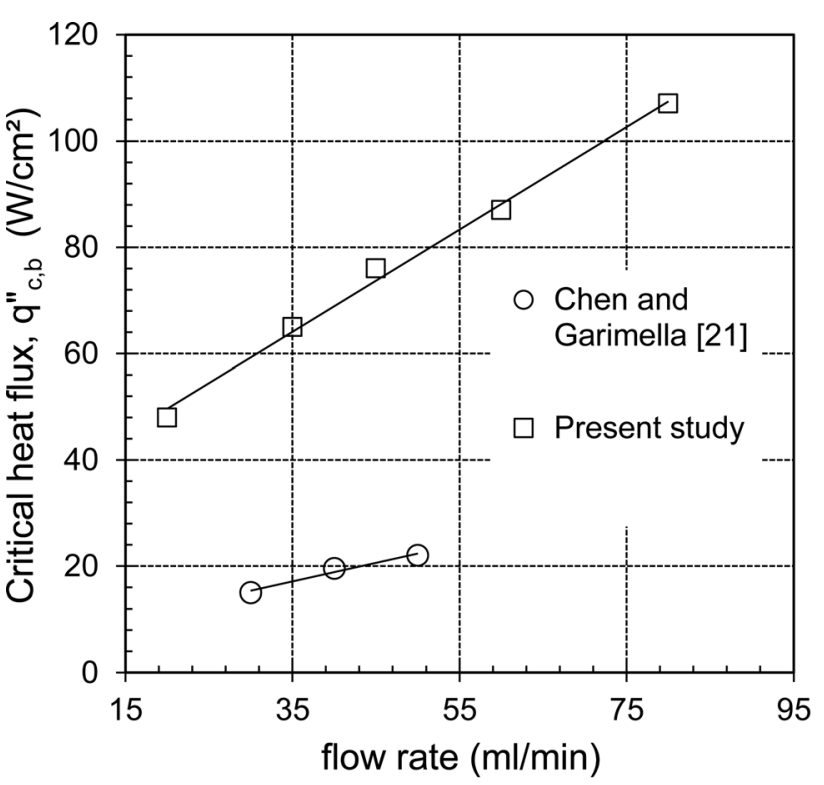

(a)

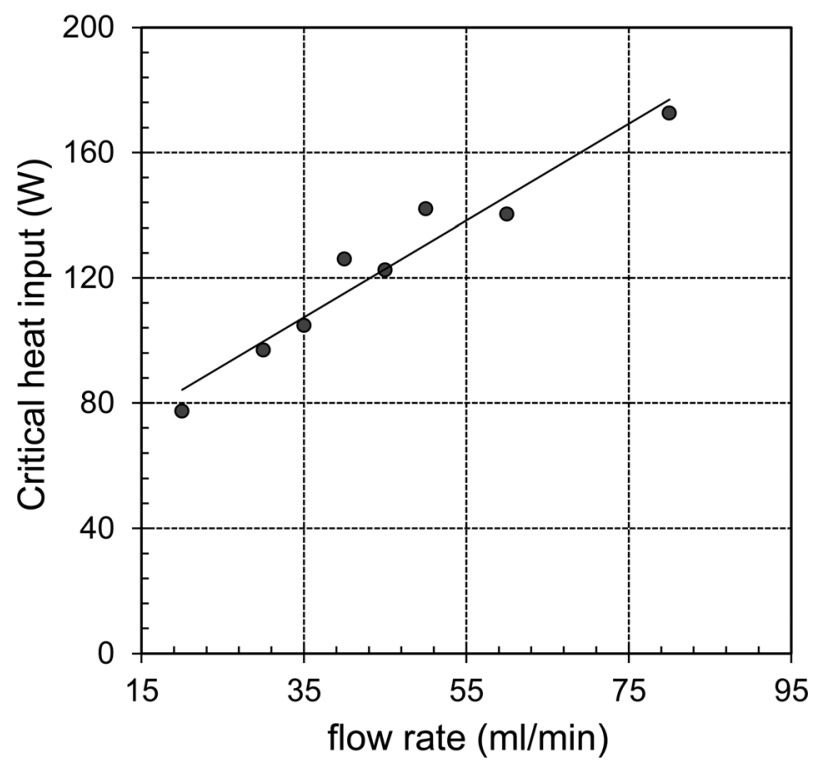

(b)

Fig. 6 (a) Critical heat flux variation with respect to the substrate base area, $A_{b}$, for FC-77 obtained in two independent studies and $(b)$ corresponding critical heat input rates

increasing heat flux in the boiling regime "d" in Fig. 4(b), more bubbles are pushed into the inlet plenum and tend to agglomerate and block the fluid from entering the microchannels even after the period of reversed flow ceases. To protect the test chip from overheating, the heat input was turned off immediately when an abrupt temperature increase near the exit was detected; a detailed visual investigation of the blocked flow due to the agglomerated bubbles at the inlet to the microchannels was thus not undertaken. However, this mechanism for the occurrence of CHF is further supported by the corresponding pressure drop measurements shown in Fig. 5 that illustrates abrupt decreases in the pressure drop across the heat sink for all the five flow rates tested when the flow at the inlet to the microchannels is blocked. At the point in time when CHF is reached, the fluid through all of the parallel microchannels is blocked by the agglomerated bubbles in the inlet plenum, which leads to an abrupt decrease in fluid flow rate through the microchannels. The abrupt decrease in flow rate through all of 
Table 1 Test parameters and fluid properties $\left(1 \mathrm{~atm}\right.$ and $\left.20^{\circ} \mathrm{C}\right)$ in the database compiled from five different tests

\begin{tabular}{|c|c|c|c|c|c|c|}
\hline & & \multirow{2}{*}{$\begin{array}{c}\text { Qu and } \\
\text { Mudawar [15] }\end{array}$} & \multicolumn{2}{|c|}{$\begin{array}{c}\text { Bowers and } \\
\text { Mudawar [14] }\end{array}$} & \multirow{2}{*}{$\begin{array}{c}\text { Chen and } \\
\text { Garimella [21] } \\
\text { Test IV }\end{array}$} & \multirow{2}{*}{$\begin{array}{c}\begin{array}{c}\text { Present } \\
\text { study }\end{array} \\
\text { Test V }\end{array}$} \\
\hline & & & Test II & Test III & & \\
\hline Fluid & & Water & R-113 & $\mathrm{R}-113$ & FC-77 & FC-77 \\
\hline \multirow[t]{7}{*}{ Properties } & Saturation temperature $\left({ }^{\circ} \mathrm{C}\right)$ & 100 & 57.4 & 57.4 & 97 & 97 \\
\hline & Latent heat $(\mathrm{kJ} / \mathrm{kg})$ & 2257 & 141.1 & 141.1 & 89 & 89 \\
\hline & Liquid density $\left(\mathrm{kg} / \mathrm{m}^{3}\right)$ & 957.9 & 1484 & 1484 & 1780 & 1780 \\
\hline & Vapor density $\left(\mathrm{kg} / \mathrm{m}^{3}\right)$ & 0.60 & 9.96 & 9.96 & 5.00 & 5.00 \\
\hline & Surface tension $(\mathrm{N} / \mathrm{m})$ & 0.0589 & 0.0136 & 0.0136 & 0.0150 & 0.0150 \\
\hline & Heat capacity $(\mathrm{kJ} / \mathrm{kg}-\mathrm{K})$ & 4.217 & 0.922 & 0.922 & 1.046 & 1.046 \\
\hline & Thermal conductivity (W/m-K) & 0.680 & 0.070 & 0.070 & 0.063 & 0.063 \\
\hline \multirow[t]{3}{*}{ Substrate } & Material & Copper & Copper & Copper & Copper & Silicon \\
\hline & Length (mm) & 44.8 & 28.6 & 28.6 & 25.4 & 12.7 \\
\hline & Width $(\mathrm{mm})$ & 10.0 & 28.6 & 28.6 & 25.4 & 12.7 \\
\hline \multirow[t]{2}{*}{ Heated area } & Length, $\mathrm{L}_{\mathrm{h}}(\mathrm{mm})$ & 44.8 & 10.0 & 10.0 & 25.4 & 12.7 \\
\hline & Width, $\mathrm{W}_{\mathrm{h}}(\mathrm{mm})$ & 10.0 & 10.0 & 10.0 & 25.4 & 12.7 \\
\hline \multirow[t]{6}{*}{ Microchannels } & Number of channels & 21 & 17 & 3 & 10 & 60 \\
\hline & Channel shape & Rectangular & Circular & Circular & Rectangular & Rectangular \\
\hline & Width, (mm) & 0.215 & $\mathrm{n} / \mathrm{a}$ & $\mathrm{n} / \mathrm{a}$ & 0.504 & 0.100 \\
\hline & Height, $(\mathrm{mm})$ & 0.821 & $\mathrm{n} / \mathrm{a}$ & $\mathrm{n} / \mathrm{a}$ & 2.500 & 0.389 \\
\hline & Hydraulic diameter $\mathrm{D}_{\mathrm{h}}(\mathrm{mm})$ & 0.341 & 0.510 & 2.540 & 0.839 & 0.159 \\
\hline & Effective heated diameter $\mathrm{D}_{\mathrm{e}}(\mathrm{mm})$ & 0.380 & 0.510 & 2.540 & 0.916 & 0.177 \\
\hline \multirow[t]{3}{*}{ Flow parameters } & Mass flow rate, $\dot{\mathrm{m}}\left(10^{-3} \mathrm{~kg} / \mathrm{s}\right)$ & $0.32-1.32$ & $0.45-1.65$ & $0.46-2.43$ & $0.89-1.48$ & $0.59-2.37$ \\
\hline & Mass flux, $\mathrm{G}\left(\mathrm{kg} / \mathrm{s}-\mathrm{m}^{2}\right)$ & $85.9-368.4$ & $130-476.0$ & $30.0-160.0$ & $70.5-117.5$ & $253.7-1015.0$ \\
\hline & Inlet temperature $\left({ }^{\circ} \mathrm{C}\right)$ & $30.0,60.0$ & 37.4 & 37.4 & 80.0 & 71.0 \\
\hline \multirow[t]{3}{*}{ Correlation parameters } & $\mathrm{L}_{\mathrm{h}} / \mathrm{D}_{\mathrm{e}}$ & 117.8 & 3.94 & 19.6 & 27.7 & 71.7 \\
\hline & $\mathrm{We} / \mathrm{G}^{2}=\mathrm{L} /\left(\sigma \cdot \rho_{1}\right),\left(\mathrm{kg} / \mathrm{s}-\mathrm{m}^{2}\right)^{-2}$ & 0.00079404 & 0.00045132 & 0.00045132 & 0.00105810 & 0.00052905 \\
\hline & $\rho_{\mathrm{v}} / \rho_{1}$ & 0.00062637 & 0.00496252 & 0.00496252 & 0.0031243 & 0.00312432 \\
\hline
\end{tabular}

the microchannels is the reason for the decrease in the pressure drop when $\mathrm{CHF}$ is reached. When the flow through all of the parallel microchannels is (suddenly) blocked, the pressure transducer first responds to this sudden decrease in the flow rate, and thus records a decrease in the pressure drop. It is possible that after this condition, the pressure at the inlet plenum may build up, which however was not allowed to proceed in the experiments to preserve the integrity of the test setup. If the instabilities were suppressed, for instance, by throttling the flow at the entrance to each microchannel, the CHF may be increased as suggested by Bergles and Kandlikar [23].

\section{Results and Analysis}

The CHF values (with respect to the heat sink base area) deduced from Fig. $4(b)$ at the five total flow rates through the microchannels are plotted in Fig. 6(a); also included in Fig. 6(a) are CHF data obtained by Chen and Garimella [21] for the same coolant (FC-77) but in a heat sink of a larger base area $(25.4 \mathrm{~mm} \times 25.4 \mathrm{~mm})$ containing ten microchannels, each $504 \mu \mathrm{m}$ wide and $2.5 \mathrm{~mm}$ deep. Figure $6(b)$ plots the corresponding total heat input rates at the heat sink base when CHF occurs. The data scatter in Fig. 6(b) is quantified by a mean absolute error (MAE) expressed as

$$
\mathrm{MAE}=\frac{1}{\mathrm{M}} \sum \frac{\left|\dot{\mathrm{q}}_{\mathrm{CHF}, \mathrm{cf}}-\dot{\mathrm{q}}_{\mathrm{CHF}, \exp }\right|}{\dot{\mathrm{q}}_{\mathrm{CHF}, \exp }} \times 100 \%
$$

of $4.75 \%$, where $\dot{\mathrm{q}}_{\mathrm{CHF}, \mathrm{cf}}$ at each flow rate is calculated from a linear curve-fit to the eight data points. The critical heat inputs at a given total flow rate obtained in the two different studies are almost identical and exhibit a linear dependence on flow rate. It is the substrate base area of the heat sink that distinguishes the two sets of CHF given in Fig. 6(a).
The CHF phenomenon during flow boiling in heat sinks containing multiple parallel microchannels is further investigated by compiling a database of a total of $49 \mathrm{CHF}$ data points from four separate studies including the present study. The database covers results for water, R-113, and FC-77, and includes a wide range of channel dimensions and flow conditions. Table 1 lists fluid properties and the test parameters of the five tests included in the database. Figure 7 plots the critical heat inputs for all 49 data points. It is seen that the critical heat input has a strong dependence on the

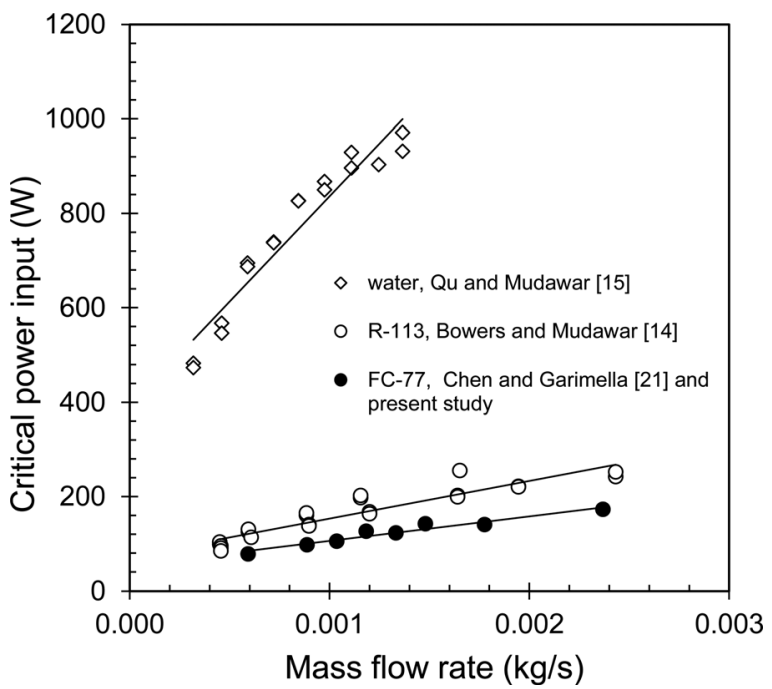

Fig. 7 Critical heat input rates as a function of mass flow rate for three fluids (water, R-113, and FC-77) 


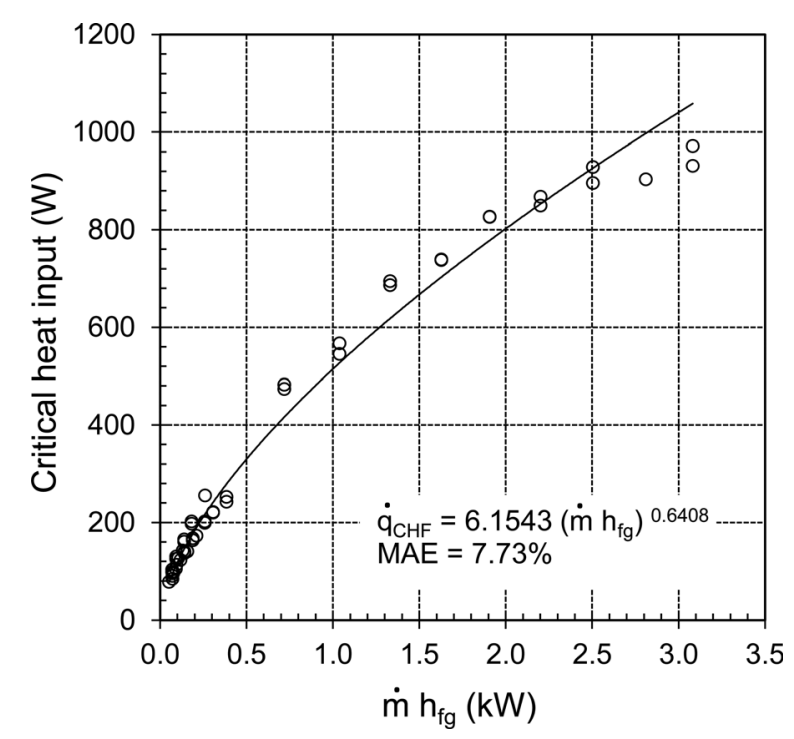

Fig. 8 Critical heat input rate as a function of $\dot{m} h_{\mathrm{fg}}$ for the three different fluids (water, R-113, FC-77)

fluid and the flow rate; for a given fluid, it increases with increasing flow rate. It is noted that the data for R-113 in Fig. 7 contain two sets of data for boiling in parallel minichannels and microchannels. Within the scatter quantified by an MAE value of $9.61 \%$, these data again show as with FC-77 earlier that for a given fluid, the critical heat input is independent of the details of the microchannel heat sink (channel size, number of channels, substrate material, and base area).

Figure 8 shows the critical heat inputs for the $49 \mathrm{CHF}$ data points in the database plotted as a function of the product of $\dot{m}$ and $h_{\mathrm{fg}}$. The critical heat inputs follow a well-defined trend that is independent of the fluid and the details of the heat sink

$$
\dot{\mathrm{q}}_{\mathrm{CHF}}=6.1543\left(\dot{\mathrm{m}}_{\mathrm{fg}}\right)^{0.6408}
$$

The practical implication of Eq. (8) is that for a selected fluid at a given flow rate, the upper limit of the cooling capacity for boiling in a heat sink with multiple parallel microchannels is set, and is independent of the design of the heat sink. Once the area on which CHF is to be based is clearly identified, the critical heat flux is readily calculated. Predictions from Eq. (8) represent the experimental data to within an MAE value of $7.73 \%$. While Eq. (8) is subject to verification of its general applicability with a larger $\mathrm{CHF}$ database for flow boiling in microchannel heat sinks, it implies that it is not the microchannel heat sink design, but the availability of liquid for evaporation, i.e., the product of flow rate and latent heat of the working fluid, that limits the heat transfer rate when CHF was reached. The constants in the equation may be attributed to the effect of flow instabilities. As noted in Sec. 4, the critical heat input would be enhanced provided that a method of suppressing the flow instabilities was employed.

The thermodynamic exit quality for each of the data points included in the database is calculated using

$$
x_{\mathrm{e}, \mathrm{c}}=\frac{1}{\mathrm{~h}_{\mathrm{fg}}}\left[\frac{\dot{\mathrm{q}}_{\mathrm{CHF}}}{\dot{\mathrm{m}}}-\mathrm{c}_{\mathrm{P}}\left(\mathrm{T}_{\mathrm{sat}}-\mathrm{T}_{\mathrm{in}}\right)\right]
$$

and plotted in Fig. 9. It is seen that for R-113 and FC-77, the exit qualities are much higher than those for water. The exit qualities at low flow rates for R-113 and FC-77 are greater than 1.0 indicating that the vapor is superheated at the exit when CHF occurs. The vapor quality can exceed a value of unity as CHF occurs

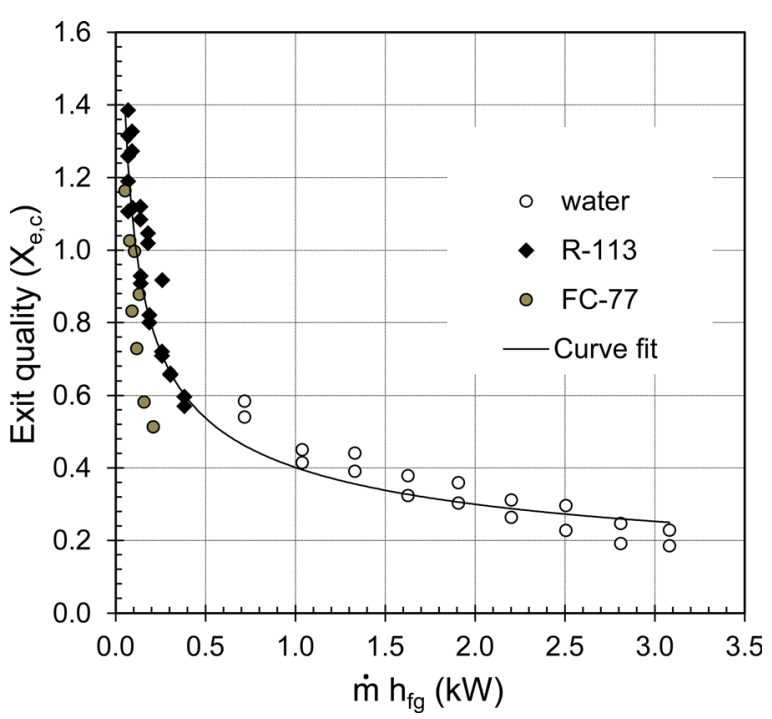

Fig. 9 Thermodynamic exit quality when CHF occurs in the microchannels

since the heat input downstream is smeared by conduction through the microchannel substrate to the upstream region, thus postponing an abrupt temperature rise at CHF. The possibility for the exit quality to be greater than 1.0 for flow boiling in multiple parallel microchannels when CHF occurs is an important distinction from flow boiling in single channels based on the correlation for the critical quality given in Eq. (1) that is invariably less than 1.0

\section{Prediction of Critical Heat Flux}

Figure 10(a) shows the predicted CHF values from Eqs. (2) and (3) compared to the measured CHF for FC-77 from Ref. [21] and the present study, in which the heat fluxes are with respect to the total wetted area of microchannels. The correlation in Eq. (3) predicts the $\mathrm{CHF}$ data for FC-77 very well whereas Eq. (2) overpredicts the experimental data by 40-70\%.

A new correlation is proposed in terms of Weber number, density ratio, $\rho_{\mathrm{v}} / \rho_{1}$, length-diameter ratio, $\mathrm{L} / \mathrm{D}_{\mathrm{e}}$, based on the 49 $\mathrm{CHF}$ data points in the database compiled in this work

$$
\frac{\mathrm{q}_{\mathrm{c}, \mathrm{p}}^{/ /}}{\mathrm{Gh}_{\mathrm{fg}}}=40.0\left(\frac{\rho_{\mathrm{v}}}{\rho_{\mathrm{l}}}\right)^{1.12} \mathrm{We}^{-0.24}\left(\frac{\mathrm{L}_{\mathrm{h}}}{\mathrm{D}_{\mathrm{e}}}\right)^{-0.34}
$$

The predictions from Eq. (10) are compared against the experimental CHF data in Fig. 10(b). The predictions match the experiments very well, with an MAE of $7.67 \%$.

An alternative correlation is motivated by the results in Fig. 8, with the heat transfer area being the total wetted channel area of the microchannels, $A_{p}$

$$
\dot{\mathrm{q}}_{\mathrm{c}, \mathrm{p}}=\frac{6.1543}{\mathrm{~A}_{\mathrm{P}}}\left(\dot{\mathrm{m}}_{\mathrm{fg}}\right)^{0.6408}
$$

This correlation is shown in Fig. 10(c) that agrees with experiments to within an accuracy of $7.62 \%$. While the predictions from Eqs. (10) and (11) are both very good, the latter is significantly simpler, with the latent heat being the only fluid property needed in the prediction. 


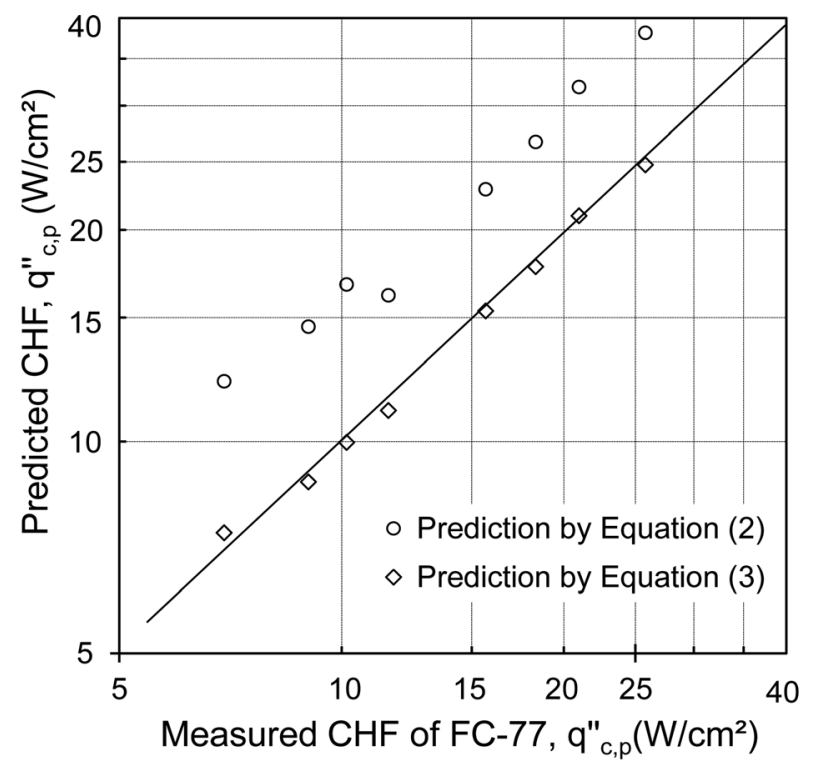

(a)

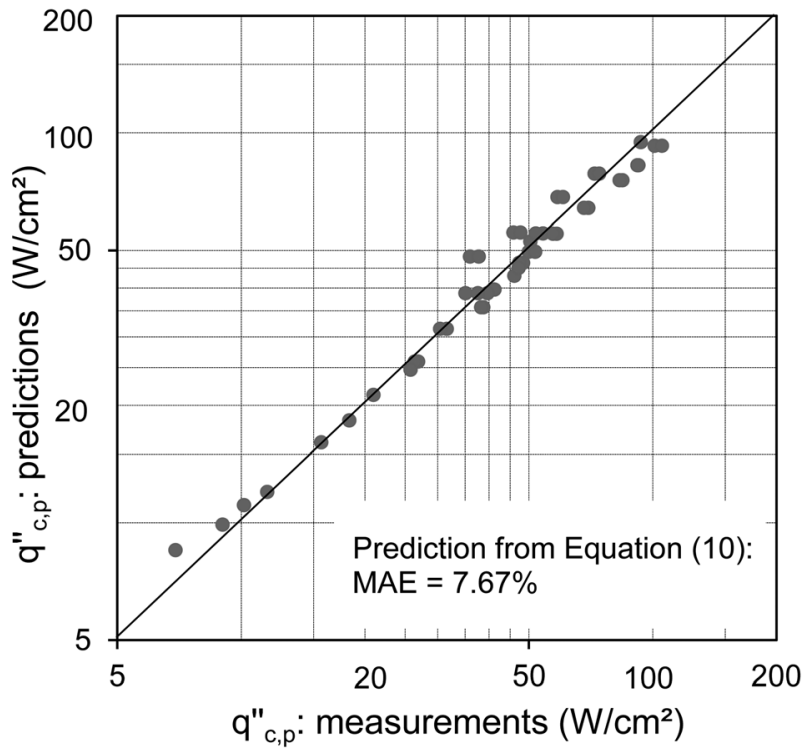

(b)

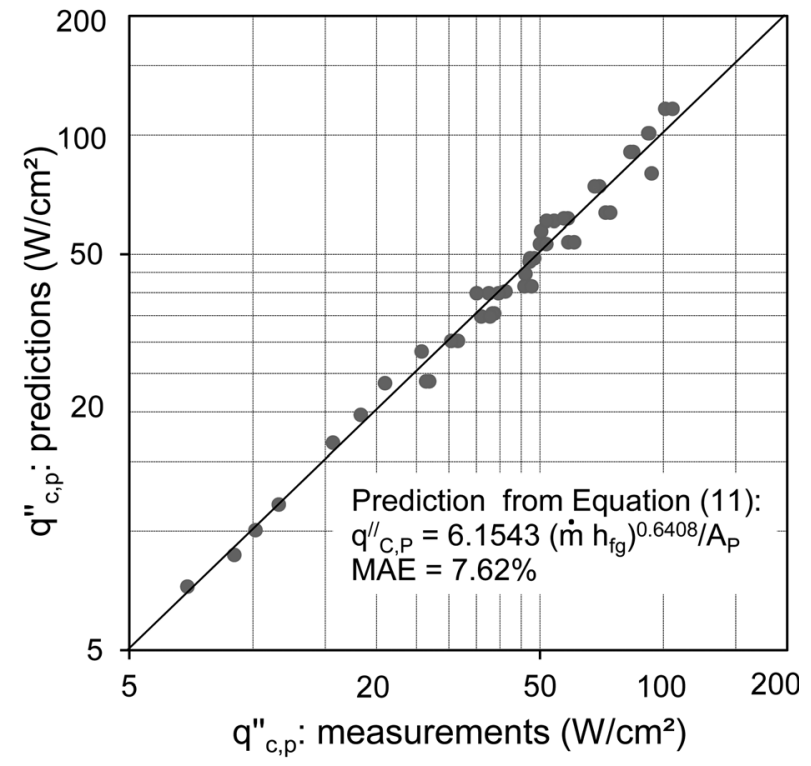

(c)

Fig. 10 (a) Comparison of predictions from Eqs. (2) and (3) against measured CHF for FC-77 obtained in the present work and a previous study by the authors [21]; $(b)$ comparison of predictions from Eq. (10) against the database compiled in this work (Table 1); and (c) comparison of predictions from Eq. (11) against the database (Table 1)

\section{Summary and Conclusions}

The critical heat flux for the boiling of FC-77 in a silicon thermal test die containing 60 parallel microchannels (each $100 \mu \mathrm{m}$ wide and $389 \mu \mathrm{m}$ deep) was measured at five total flow rates through the microchannels in the range of $20-80 \mathrm{ml} / \mathrm{min}$ corresponding to mass fluxes of $253.7-1015.0 \mathrm{~kg} / \mathrm{s}-\mathrm{m}^{2}$. A database of $49 \mathrm{CHF}$ data points obtained in five experiments from four independent studies for water, R-113, and FC-77 was compiled and analyzed. The major findings of this study are summarized as follows:

(1) As CHF is approached, extended wall dryout in the downstream region of the microchannels leads to large increases in the wall temperature for small increases in heat flux. As $\mathrm{CHF}$ is reached, an abrupt increase in wall temperature is observed, with a corresponding abrupt decrease in heat transfer coefficient. The pressure drop measurements show a sharp decrease in pressure drop across the microchannels under these conditions.

(2) The CHF is caused by wall dryout near the exit, which is in turn attributed to flow reversal in the upstream region of the microchannels. As the flow is reversed, bubbles pushed back into the inlet plenum agglomerate and block the flow into the microchannels; this appears to be the specific mechanism leading to the occurrence of CHF.

(3) At a given flow rate, the critical heat input (total heat transfer rate to the coolant as CHF occurs) was found to depend only on the fluid and is independent of other details of the microchannel heat sink. This observation is verified to hold for results from independent studies of water, R-113, and FC-77 tested in different microchannel heat sinks.

(4) The critical heat input for flow boiling in microchannels follows a clear trend with the product of $\dot{\mathrm{m}}$ and $\mathrm{h}_{\mathrm{fg}}$ leading to a simple power-law correlation for critical heat input. 
(5) Compared with a more complex, alternate correlation also proposed in this work that incorporates the vapor/liquid density, Weber number, and length-diameter ratio, the simple power-law correlation of the critical heat input provides an equally accurate prediction of $\mathrm{CHF}$ in the database. The practical implication of this simple correlation is that it predicts the upper limit of cooling capacity of microchannel two-phase cooling technologies based merely on the latent heat of vaporization of the fluid.

(6) When CHF occurs, the thermodynamic exit quality for water is much lower than for R-113 and FC-77, which is related to the much lower vapor/liquid density ratio of water. The exit qualities for R-113 and FC-77 at low flow rates are measured to be larger than 1.0, which is in contrast to the behavior in single channels.

\section{Acknowledgment}

Financial support for this work from the Indiana 21st Century Research and Technology Fund is gratefully acknowledged. The authors thank Bruce Myers and Darrel Peugh of Delphi Electronics and Safety, Kokomo, Indiana, for providing the silicon test piece used in this work.

\section{Nomenclature}

$A_{b}=$ heat sink substrate area $\left(\mathrm{m}^{2}\right)$

$\mathrm{A}_{\mathrm{p}}=$ total wetted channel area, $\mathrm{A}_{\mathrm{p}}=\mathrm{N}(2 \mathrm{H}+\mathrm{W}) \mathrm{L},\left(\mathrm{m}^{2}\right)$

$\mathrm{c}_{\mathrm{p}}=$ heat capacity $(\mathrm{J} / \mathrm{kg}-\mathrm{K})$

$\mathrm{D}_{\mathrm{e}}=$ effective channel diameter, $(\mathrm{mm})$

$\mathrm{D}_{\mathrm{h}}=$ channel hydraulic diameter, $(\mathrm{mm})$

$\mathrm{G}=$ mass flux, $\left(\mathrm{kg} / \mathrm{s}-\mathrm{m}^{2}\right)$

$\mathrm{h}=$ heat transfer coefficient $\left(\mathrm{W} / \mathrm{m}^{2}-\mathrm{K}\right)$

$\mathrm{H}=$ height of microchannels $(\mathrm{m})$

$\mathrm{h}_{\mathrm{fg}}=$ latent heat, $(\mathrm{kJ} / \mathrm{kg})$

$\mathrm{k}=$ thermal conductivity of substrate (silicon) $(\mathrm{W} / \mathrm{m}-\mathrm{K})$

$\mathrm{L}_{\mathrm{h}}=$ channel heated length, $(\mathrm{mm})$

$\mathrm{L}=$ channel length, $(\mathrm{mm})$

$\mathrm{M}=$ number of data points

$\dot{\mathrm{m}}=$ mass flow rate $(\mathrm{kg} / \mathrm{s})$

$\mathrm{N}=$ number of channels

$\dot{\mathrm{q}}_{\mathrm{CHF}}=$ critical heat input $(\mathrm{W})$

$\dot{\mathrm{q}}_{\text {fluid }}=$ rate of heat transfer to the fluid (W)

$\dot{\mathrm{q}}_{\text {loss }}=$ heat loss $(\mathrm{W})$

$\dot{\mathrm{q}}_{\text {total }}=$ total heat dissipation $(\mathrm{W})$

$\mathrm{q}_{\mathrm{b}}^{/ /}=$heat flux with respect to base area $\left(\mathrm{W} / \mathrm{cm}^{2}\right)$

$\mathrm{q}_{\mathrm{c}, \mathrm{b}}^{/ / /}=$critical heat flux with respect to base area $\left(\mathrm{W} / \mathrm{cm}^{2}\right)$

$\mathrm{q}_{\mathrm{c}, \mathrm{p}}=$ critical heat flux with respect to total channel wetted area $\left(\mathrm{W} / \mathrm{cm}^{2}\right)$

$\mathrm{T}_{\mathrm{b}}=$ heat sink base temperature $\left({ }^{\circ} \mathrm{C}\right)$

$\mathrm{T}_{\text {in }}=$ fluid temperature at the inlet $\left({ }^{\circ} \mathrm{C}\right)$

$\mathrm{T}_{\text {sat }}=$ fluid saturation temperature $\left({ }^{\circ} \mathrm{C}\right)$

$\mathrm{T}_{\mathrm{W}}=$ local wall temperature $\left({ }^{\circ} \mathrm{C}\right)$

$t_{b}=$ distance from the heat sink base to the bottom of the channel

$\mathrm{W}=$ width of microchannels $(\mathrm{m})$

$\mathrm{We}=$ Weber number

$\mathrm{x}=$ distance of temperature sensors from the inlet (mm)

$x_{\mathrm{e}, \mathrm{c}}=$ thermodynamic exit quality at CHF

\section{Greek}

$\Delta \mathrm{h}_{\text {in }}=$ enthalpy difference from the saturation state $(\mathrm{kJ} / \mathrm{kg})$

$\rho_{1}=$ liquid density, $\left(\mathrm{kg} / \mathrm{m}^{3}\right)$

$\rho_{\mathrm{v}}=$ vapor density, $\left(\mathrm{kg} / \mathrm{m}^{3}\right)$

$\sigma=$ surface tension, $(\mathrm{N} / \mathrm{m})$

\section{References}

[1] Garimella, S. V., Fleisher, A. S., Murthy, J. Y., Keshavarzi, A., Prasher, R., Patel, C., Bhavnani, S., Venkatasubramanian, R., Mahajan, R., Joshi, Y., Sammakia, B., Myers, B. A., Chorosinski, L., Baelmans, M., Sathyamurthy, P., and Raad, P., 2008, "Thermal Challenges in Next Generation Electronic Systems," IEEE Trans. Compon. Packag. Technol., 31(4), pp. 801-815.

[2] Hall, D. D., and Mudawar, I., 2000, "Critical Heat Flux for Water in Tubes-I. Compilation and Assessment of World CHF Data," Int. J. Heat Mass Transfer, 43, pp. 2573-2604.

[3] Lowdermilk, W. H., Lanzo, C. D., and Siegel, B. L., 1958, "Investigation of Boiling Burnout and Flow Stability for Water Flowing in Tubes," NACA TN 4382, National Advisory Committee for Aeronautics.

[4] Weatherhead, R. J., 1963, "Heat Transfer, Flow Instability, and Critical Heat Flux for Water in a Small Tube at 200 psia," ANL-6715, Argonne National Laboratory.

[5] Becker, K. M., 1970, "Burnout Measurements in Vertical Round Tubes, Effect of Diameter," AE-TPM-RL-1260, Aktiebolaget Atomenergi.

[6] Katto, Y., 1978, "A Generalized Correlation of Critical Heat Flux for the Forced Convection Boiling in Vertical Uniformly Heated Round Tubes," Int. J. Heat Mass Transfer, 21, pp. 1527-1542.

[7] Katto, Y., 1979, "A Generalized Correlation of Critical Heat Flux for the Forced Convection Boiling in Vertical Uniformly Heated Round Tubes-a Supplementary Report,” Int. J. Heat Mass Transfer, 22, pp. 783-794.

[8] Y. Katto, 1979, “An Analysis of the Effect of Inlet Subcooling on Critical Heat Flux of Forced Convection Boiling in Vertical Uniformly Heated Tubes," Int. J. Heat Mass Transfer, 22, pp. 1567-1575.

[9] Y. Katto, 1981, "General Features of CHF of Forced Convection Boiling in Uniformly Heated Rectangular Channels," Int. J. Heat Mass Transfer, 24, pp. 1413-1419.

[10] Lazarek, G. M., and Black, S. H., 1982, "Evaporative Heat Transfer, Pressure Drop and Critical Heat Flux in a Small Vertical Tube With R-113," Int. J. Heat Mass Transfer, 25, pp. 945-960.

[11] Vandervort, C. L., Bergles, A. E., and Jensen, M. K., 1994, “An Experimental Study of Critical Heat Flux in Very High Heat Flux Subcooled Boiling," Int. J. Heat Mass Transfer, 37, supplement 1, pp. 161-173.

[12] Yu, W., France, D. M., Wambsganss, M. W., and Hull, J. R., 2004, "Two-Phase Pressure Drop, Boiling Heat Transfer, and Critical Heat Flux to Water in a Small-Diameter Horizontal Tubes,” Int. J. Multiphase Flow, 28, pp. 927-941.

[13] Tong, L. S., 1972, "Boiling Crisis and Critical Heat Flux," U.S. Atomic Energy Commission, Technical Report No. TID-25887.

[14] Bowers, M. B., and Mudawar, I., 1994, "High Flux Boiling in Low Flow Rate, Low Pressure Drop Mini-Channel and Micro-Channel Heat Sinks," Int. J. Heat Mass Transfer, 37, pp. 321-332.

[15] Qu, W., and Mudawar, I., 2004, "Measurement and Correlation of Critical Heat Flux in Two-Phase Microchannel Heat Sinks," Int. J. Heat Mass Transfer, 47, pp. 2045-2059.

[16] Katto, Y., and Ohno, H., 1984, "An Improved Version of the Generalized Correlation of Critical Heat Flux for the Forced Convective Boiling in Uniformly Heated Vertical Tubes," Int. J. Heat Mass Transfer, 27, pp. 16411648.

[17] Lezzi, A. M., Niro, A., and Beretta, G. P., 1994, "Experimental Data of CHF for Forced Convection Water Boiling in Long Horizontal Capillary Tubes," Heat Transfer 1994: Proceedings of the 10th International Heat Transfer Conference, G. F. Hewitt, ed., Institution of Chemical Engineers, Rugby, UK, 7, pp. 491-496.

[18] Roach, G. M., Jr., Abdel-Khalik, S. I., Ghiaasiaan, S. M., Dowling, M. F., and Jeter, S. M., 1999, "Low-Flow Critical Heat Flux in Heated Microchannels," Nucl. Sci. Eng., 131, pp. 411-425.

[19] Chen, T., and Garimella, S. V., 2006, "Measurements and High-Speed Visualizations of Flow Boiling of a Dielectric Fluid in a Silicon Microchannel Heat Sink,” Int. J. Multiphase Flow, 32, pp. 957-971.

[20] Harirchian, T., and Garimella, S. V., 2009 "Effects of Channel Dimension, Heat Flux, and Mass Flux on Flow Boiling Regimes in Microchannels," Int. J. Multiphase Flow, 35, pp. 349-362.

[21] Chen, T., and Garimella, S. V., 2007, "Flow Boiling Heat Transfer to a Dielectric Fluid in a Microchannel Heat Sink," IEEE Trans. Compon. Packag. Technol., 30(1), pp. 24-31.

[22] Roday, A. P., and Jensen, M. K., 2009, "A Review of Critical Heat Flux Condition in Mini- and Microchannels,” J. Mech. Sci. Technol., 23, pp. 2529 2547.

[23] Bergles, A. E., and Kandlikar, S. G., 2005, "On the Nature of Critical Heat Flux in Microchannels," J. Heat Transfer, 127, pp. 101-107.

[24] Kuo, C. J., and Peles, Y., 2008, "Critical Heat Flux of Water at Subatmospheric Pressures in Microchannels," J. Heat Transfer, 130, p. 072403.

[25] Chen, T., and Garimella, S. V., 2006, "Effects of Dissolved Air on Subcooled Flow Boiling of a Dielectric Coolant in a Microchannel Heat Sink," J. Electron. Packag., 128, pp. 398-404.

[26] Kline, S. J., and McClintock, F. A., 1953, "Describing Uncertainties in SingleSample Experiments," Mech. Eng., 75, pp. 3-8.

[27] Chen, T., and Garimella, S. V., 2011, "Local Heat Transfer Distribution and Effect of Instabilities during Flow Boiling in a Silicon Microchannel Heat Sink," Int. J. Heat Mass Transfer, 54, pp. 3179-3190. 